\title{
A contextual perspective on presupposition, with reference to translation studies
}

\author{
Ying Cui and Yanli Zhao \\ School of Translation Studies, Shandong University, Weihai, P.R. China \\ Email: cuiyingcui@163.com; 464944884@qq.com
}

\begin{abstract}
This paper aims to elaborate on the notion of 'presupposition' from the contextual perspective in consideration of translation studies. Presupposition plays an important role for researchers to understand translation or the process of translating, work out the implications of translated texts, and explain various issues concerning translation. As far as translation is concerned, context can be regarded as the source for presuppositions, as translators usually work according to their own presuppositions regarding the target readers and context. In this study, we have established a framework of presuppositions relevant to translation research, covering such aspects as human needs, communicative rules, and textualisation strategies. A case study is provided to demonstrate how the presuppositions are applied in discussing translation issues.
\end{abstract}

Keywords: presupposition, context, translation

\section{Introduction}

This research is based on a prior study which reviews semantic, pragmatic, and experiential approaches to presupposition and concludes that context actually determines presupposition (see Cui 2013). According to Tannen (2007:37), no text of any kind would be comprehensible without shared context and background. Context is also essential for understanding presupposition in translation. Presupposition plays an important role in translators' work and decision-making, and it is helpful for explaining various issues related to translation. However, studies on presupposition in the light of translation are rare, and we have not found any similar explorations. This study aims to establish a framework of presuppositions from the perspective of context, and to provide reference for translators. First of all, we will briefly review the research on presupposition in Linguistics.

\section{Three approaches to presupposition}

In the field of Linguistics, there are three major approaches to presupposition. The first is semantic presupposition which is based on the concept of 'truth value'. It implies that proposition $\mathrm{P}$ presupposes proposition $\mathrm{Q}$ if, and only if, $\mathrm{Q}$ is necessitated both by $\mathrm{P}$ and by the negation of $\mathrm{P}$ (Stalnaker 1998:61). In other words, presupposition is seen as a precondition for 
a sentence to have a truth value. In contrast, the pragmatic approach is not concerned with logic or truth value; instead, it is more about a propositional attitude than a semantic relation. To be more specific, pragmatic presuppositions involve speakers' and hearers' knowledge, expectations, desires, interests, claims, and attitudes towards the world (Mey 2001:186). Therefore, pragmatic presuppositions have been located in a wider communicative setting, covering such contextual factors as speaker, hearer, belief, appropriateness, and mutual knowledge (Segerdahl 1996).

Both the semantic and pragmatic approaches encounter problems like the defeasibility problem, as some presuppositions are liable to disappear in certain contexts (Abbott 2006). Presuppositions are defeasible whenever background assumptions about the world or specific communicative situations are not compatible with what is presupposed. For instance, in the sentence, "Jane cried before she left him", the word "before" presupposes that she left him. However, in the sentence, "Jane had a dream and in the dream she cried before she left him", the word "before" apparently does not carry the presupposition that she left him; on the contrary, it implies that she did not leave him, because common sense has it that if something is dreamed, it is not real. (For further discussion on defeasibility, see Cui 2013:199-200.) While neither the semantic nor the pragmatic approach can properly solve this problem, the experiential approach offers an explanation from a different perspective.

In the experiential approach, context is regarded as the determining factor for the defeasibility or projection of presupposition. For example, in the sentence, "Mary imagined that she had stopped smoking", the word "stop" presupposes that Mary had smoked before. According to the explanation of the experiential approach, whether the presupposition can ascend to the complex sentence depends on whether the speaker knows if Mary smoked before or not. If the speaker knows Mary had smoked before, then the presupposition can be applied to the main sentence; if the speaker does not know, whether the presupposition can survive depends on the reality. (For further discussion on the experimental approach, see Cui 2013:201-205.) While it may be questioned that the experiential explanations are subjective, subjectification is closely related to our cognition of information and the organisation of information in a context (Ferrari and Sweetser 2012:55).

We can see that within the three approaches, the pragmatic and the experiential ones are concerned with context. The pragmatic approach applies context in its general sense and covers almost everything that may be involved in the communication. For this reason, there is no fixed or workable framework to which translation studies can refer. In addition, the pragmatic approach is not clear about the relationship between context and presupposition, and in many cases the two are confused. The experiential approach is clear about the relation between context and presupposition. Its illustration of presupposition is essentially a matter of contextual compatibility, and presuppositions are regarded to be determined by context. This is in line with the practice of translation. Translators need to consider the reception of their translations in the target context and work according to their presuppositions about the target readers. In this sense, the target context or translators' perception thereof actually determines what presuppositions translations may carry. As in the pragmatic approach, the components of context are not explicitly analysed in the experiential studies either. In the next section, we will discuss the content and general classification of context. 


\section{Components of context}

\subsection{Review of context}

Despite its "omnipresence" in different domains, "context has remained fuzzy and seems almost impossible to come to terms with" (Fetzer 2004:3). This is why context has been regarded by Mey (in Widdowson 2004:41) as "a notoriously hard concept to deal with". A theory of context was first put forward by Malinowski (in Widdowson 2004:38), who divides context into context of culture and context of situation. In other words, context includes extralinguistic factors such as those more permanent, like speakers' cultural backgrounds, and those more immediate, like the communicative situation in discussions on discourse. Our illustration of presupposition in translation, to be presented in section 4 , covers both of these two aspects.

Applying context to the field of Linguistics dates from the mid-1960s when, with the influence of sociology and anthropology, it was realised that language cannot be analysed as a formal system as abstracted from society and culture (Georgakopoulou 1997:17). Firth (in Widdowson 2004:39) seeks to incorporate the idea of context into the theory of language and, for him, factors like the relevant features of participants as well as the character of the communicative situation must be taken into account when analysing language. However, Widdowson notes that how Firth's program operates as a means of analysis is not clear (Widdowson 1998:39).

In a more detailed way, Hymes (in Brown and Yule 1983:38-40) sets about specifying the features of context as follows: "speakers" include the addressor and the addressee; "topic" refers to what is being talked about; "setting" is to be understood both in terms of where the scene is situated in place and time, and the physical relations of interactants with respect to their postures, gestures, and facial expressions; "channel" refers to how contact between participants is being maintained; "code" refers to what language is being used; "message-form" refers to what form is intended, e.g. a chat, debate or sermon; "event" refers to the communicative event; "key" involves evaluation; and "purpose" refers to what participants intend (Brown and Yule 1983:38-40). When analysing a text, we may choose from these contextual features which are necessary to characterise a communicative event (Brown and Yule 1983:39).

\subsection{Three major divisions of context}

Although major subdivisions of context are variant and open-ended in different studies, as was shown in section 3.1, there are three foci which are "highly stable and well attested in the traditional linguistic literature" (Givón 1989:74), namely generic, deictic, and discourse foci. Firstly, the generic focus refers to the shared world and culture. It subsumes knowledge and beliefs regarding the real world, the universal cognitive systems underlying the human mind, and the universal capacities for logical inference (Givón 1989:74). In other words, generic context refers to something that is relatively more stable or universal for human beings. Context of culture, mentioned in section 3.1, falls under this category. Secondly, deictic focus refers to the shared speech situation. Three sub-categories are included: deixis, which refers to knowledge of the immediate speech situation by virtue of being together on the same scene at the same time; socio-personal relations, such as respective power, status, long-term social goals, obligations, entitlements, needs and expectations; and speech-act teleology, which refers to shifting goals of the communicative transaction (Givón 1989:75). Hymes' contextual features listed in section 3.1, which outline the factors involved in a communicative situation, belong to 
this situational context. Thirdly, discourse focus refers to shared prior text, covering propositions which are directly uttered or any other entailed propositions that hearers can derive, and meta-propositional modalities, or knowledge of the strength of belief, certainty and evidential support (Givón 1989:75).

Following the contextual framework, in this research, when viewing generic context or the most basic category, we will mainly explore human needs, which all participants share regardless of their cultural heritage. Translations are intended to realise specific aims or functions (Nord 2001:27-28). The realisation of such aims or functions is up to the target readers who have special needs to be addressed. For this reason, translators need to take into account the target readers' needs and expectations in order to improve or enhance the effect of their work in the target context. As to how to appeal to these needs, it is up to the decision of the translators, which is influenced by their presuppositions about the target readers' expectations, interests, and values. Situational context is mostly related to the immediate communicative elements such as the Co-operative Principle (CP) and Politeness Principle (PP), which are the means to gratify people's various needs or the manifestations of satisfying the needs. Under general circumstances, translators follow these communicative maxims or presuppositions about the target readers' expectations. In terms of the discourse context, we will mainly investigate the organisation of a text, especially textualisation principles which are intended to make it easier for readers to understand a text. Similarly, under general circumstances, translators follow such principles when organising translations. There are more principles or theories concerning communication or textualisation than those which have been addressed here. However, exploration in these three aspects will help to reveal translators' presuppositions about what needs the receptors of translations have, how to appeal to these needs properly in communication, and how to realise such needs gratification in textualisation. When analysing a translation, we normally start with the wording and organisation of the text - the textualisation level - then explore the functions or reasons of the textualisation - the communication level. Finally, we figure out the most fundamental reasons of designing the text in those ways - the needs-gratification level.

\section{A framework of presuppositions concerning translation}

In this section, we will elaborate on the framework of presuppositions in relation to translation studies, including the definition of "presupposition" in relation to the activity of translation, and the ways to identify such presuppositions.

\subsection{Definition of presupposition}

When studying presupposition in translation, the purely logic approach does not work, as translators work in a context and need to consider the reception of their works in the target context. In fact, concerning the research on presupposition, it is claimed that the elements interesting to translation studies are often "those which the linguists would like to put beyond the pale" (Fawcett 1998:123). Viewed from the contextual perspective in the field of Translation, presupposition can be regarded as translators' assumptions about the target context and the target readers, especially their needs and expectations. As to the methods of identifying presuppositions, "even with the best of wills and the cleverest techniques", sometimes it is impossible to identify all the presuppositions (Mey 2001:188). In the present investigation, the sources for presupposed information in the translation are analysed with reference to the context 
framework presented in section 3.2. Presuppositions can be determined, though never exhaustively, by referring to the contextual framework with its specified components, as will be explained in section 4.2. The viewpoint of regarding context as sources for presuppositions is also found in Givón (1989:135-137), where such presuppositions are considered to be based on "contextual assumptions" (Levinson 1983:167).

\subsection{Identification of presuppositions}

As clarified in section 4.1, we have taken a contextual perspective to explore presuppositions in connection with translation. Translation is an activity that takes place in context, and context covers almost everything involved in communication, from the readers' knowledge and social background to the co-text. As a result, investigation in this regard is potentially endless, as there is always more to notice in terms of readers' knowledge than has been discovered. This is one of the reasons why, for this study, we chose to specify and confine the components of presuppositions to the discussion of human needs, the $\mathrm{CP}$ and PP for communication, and textualisation principles (as noted in section 3.2).

\subsubsection{Presuppositions related to generic context}

As a rather broad and general category, generic context refers to the shared world and culture, and in this research we choose to focus on human needs which are applicable to people of different cultural backgrounds. Texts and their translations are intended to address readers' needs, and translators have their own presuppositions about the target readers' needs as well as the proper ways to gratify these needs. Maslow's theory, which is frequently cited by all types of professionals in different industries (Stephens 2000:1), generalises three types of human needs, namely conative, cognitive, and aesthetic needs, which can serve as reference for translators. The theory is in part an attempt to account for the "unity behind the apparent diversity from culture to culture" (Maslow 1987:28). It is intended to take a closer approach to common human characteristics, and be "relatively more ultimate, more universal, and more basic than the superficial conscious desires" (Maslow 1987:28). Conative needs cover categories such as physiological needs, safety needs, social/love needs, esteem needs, and selfactualisation needs. Physiological needs are most basic, and their fulfilment is necessary for people to survive, such as food, air and water; safety needs involve security, stability and protection, freedom from fear, anxiety, and chaos, as well as the need for structure, order, law, and limits; social/love needs refer to giving and receiving affection, including the desire for association, belonging and companionship, and involves an individual's ability to exist in harmony with others; esteem needs cover self-esteem and respect from others; and selfactualisation means the desire to realise one's potential (Maslow 1987:15-22; Muchinsky 2003:375). Cognitive needs refer to the desire to know and to understand, or impulses to satisfy curiosity, to know, to explain, and to understand (Maslow 1987:23-26). Aesthetic needs refer to the desire for order, symmetry, closure, the completion of an act, a system, and structure (Maslow 1987:25-26). These needs are related to the cognitive needs of knowing/understanding, the satisfaction of which results in order, symmetry, closure, completion, system and structure. When any text is translated, it needs to address the target readers' specific needs, sometimes addressing more than one category of needs. Consciously or subconsciously, translators make decisions about how to organise and design the translation according to their presuppositions about the target readers' needs as well as the proper ways to gratify these needs. 


\subsubsection{Presuppositions related to situational context}

The situational context is more concerned with the immediate communication. As has been emphasised in section 3.2, in this study, presuppositions from a situational context are confined to the discussion concerning the CP and PP, which are ways to satisfy others' various needs (as described in section 4.2.1).

The CP has been proposed in the belief that all speakers observe these rules under normal circumstances. The principle can be elaborated on in terms of the following maxims:

- Quantity: Give the right amount of information.

- Make your contribution as informative as is required.

- Do not make your contribution more informative than is required.

- Quality: Try to make your contribution one that is true.

- Do not say what you believe to be false.

- Do not say that for which you lack adequate evidence.

- Relation: Be relevant.

- Manner: Be perspicuous.

- Avoid obscurity of expression.

- Avoid ambiguity.

- Be brief.

- Be orderly.

(Grice 1975:47)

Although the CP has been developed to analyse spoken language, it is also relevant to written language and therefore to translation (Fawcett 1997:130). For translation studies, the CP can work as a general theory of the act of translation or "intercultural cooperation", and as an instruction to translators to act properly (Fawcett 1997:130). Normally, text receivers have expectations concerning the amount of information they are provided with, the quality of the information, and the way of presenting the information. Accordingly, writers or translators hold the presuppositions that the right amount of information should be given, the information should be true and relevant, and the way of presenting the information should be clear, brief, and orderly, as receivers' expectations need to be respected.

The CP is not the only principle for communication, and politeness is a complementary rule in this regard. Politeness as a basic guideline for human interaction, which refers to the consideration of others, not only works for spoken discourse but also for written texts. It is a system of interpersonal relations to facilitate interaction by minimising the potential for conflict and confrontation (Lackoff, in Hickey 1998:54). Leech (1983:131-133; see also Hickey 1998:56) puts forward the following six maxims of politeness as an extension of the CP:

- Tact maxim: Minimise cost to other. Maximise benefit to other.

- Generosity maxim: Minimise benefit to self. Maximise cost to self.

- Approbation maxim: Minimise dispraise to other. Maximise praise to other.

- Modesty maxim: Minimise praise to self. Maximise dispraise of self.

- Agreement maxim: Minimise disagreement between self and other. Maximise agreement between self and other.

- Sympathy maxim: Minimise antipathy between self and other. Maximise sympathy between self and other. 
Leech's maxims of politeness are more flexible than the CP. Participants in communications have expectations concerning their benefit, cost, praise, dispraise, sympathy, and disagreement, which reflect their safety needs, esteem needs and social/love needs. Text producers or translators hold the presuppositions that listeners or text receivers should be given more benefit, less cost, more praise, less dispraise, less disagreement, and more sympathy. Leech's politeness

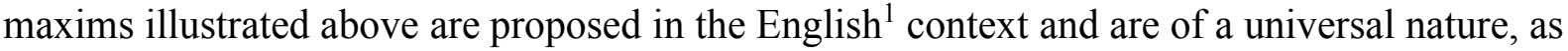
already noted. However, in specific cases, different politeness maxims exist. For example, in the Chinese context, there is a maxim which emphasises respect for others, and requires that one should show difference between the old and the young or the superior and the subordinate when addressing others (Yang 1999). Therefore, translators need to investigate the target culture and design translations in accordance with the relevant politeness maxims.

\subsubsection{Presuppositions related to discourse context}

Presuppositions related to the discourse context involve the organisation of texts. There are four basic principles in textual rhetoric, namely the processibility principle, clarity principle, economy principle, and expressibility principle. Firstly, the processibility principle recommends that texts should be designed and presented in a way that is easy for readers to decode (Leech 1983:64). It is in line with the presupposition of manner in the CP that a text should be perspicuous, avoiding obscurity and ambiguity, and the effort to make a text processible for readers is also one of the ways of being polite. Processibility of a text is mainly to gratify readers' cognitive needs to know/understand. Secondly, the clarity principle suggests that texts be presented in a clear way with enough detail so that they are easy for readers to understand (Leech 1983:66). Similarly, clarity of text is in keeping with the presuppositions of manner and information quantity in the $\mathrm{CP}$, which also helps to satisfy readers' cognitive needs to know/understand. Thirdly, the economy principle, which is almost "at war" with the clarity principle, aims to shorten a text while keeping the message unimpaired in order to reduce the amount of time and effort involved in the process of comprehension (Leech 1983:67). This is related to the presupposition of quantity in the $\mathrm{CP}$ that only the necessary amount of information is needed, and the presupposition of manner that a message should be presented in a brief way, which also helps to satisfy readers' cognitive needs to know/understand. Fourthly, the expressivity principle is mainly concerned with effectiveness in a broad sense, which includes both efficiency and aesthetic aspects of communication (Leech 1983:68). In this way, in addition to cognitive needs, readers' aesthetic needs are addressed.

Like presuppositions in the CP and PP, presuppositions concerning textualisation may apply differently to different contexts and to variable degrees (Leech 1983:69). Being processible is the fundamental condition for readers to proceed, being clear is helpful for receivers to work out the textual implications, being brief makes a text easier to be remembered than complicated expressions, and being expressible makes a text stand out - any deviation can attract receivers' attention. Generally speaking, text receivers expect that a text should be processible, clear, economical, and expressible; accordingly, text producers or translators hold the presuppositions that a text should be processible, clear, economical, and expressible.

\footnotetext{
${ }^{1}$ By "English", we do not refer to a specific country or region; instead, we pay more attention to its general implications, especially the cultural elements shared by people who speak English. This is partly because the English texts in our data are intended for those who are English-speaking, and no region has been specified.
} 


\subsection{Summary}

To summarise, as demonstrated in Table 1, the presuppositions to be referred to later in our analysis mainly cover those arising from generic, situational, and discourse contexts. While some of these values are proposed in a particular context, they are shared by other contexts, though there may be differences in particular cases. There are more presuppositions that can be applied to explain communicative situations, however, as mentioned in section 3.2, these presuppositions include target readers' needs to be gratified, general rules of communication, and principles of text organisation.

Table 1. Framework of presuppositions in relation to translation

\begin{tabular}{|l|l|}
\hline Context category & Presuppositions \\
\hline 1. Generic context & $\begin{array}{l}\text { People have conative, cognitive and aesthetic needs to be } \\
\text { gratified. }\end{array}$ \\
\hline 2. Situational context & $\begin{array}{l}\text { One should provide the right amount of information to others; } \\
\text { the information one provides should be true and relevant; the } \\
\text { way of presenting the information should be clear, brief and } \\
\text { orderly. } \\
\text { One should be polite to others, such as by giving others more } \\
\text { benefit and praise, and showing more agreement and sympathy. }\end{array}$ \\
\hline 3. Discourse context & $\begin{array}{l}\text { A text should be organised with reference to the processibility, } \\
\text { clarity, economy, and expressibility principles. }\end{array}$ \\
\hline
\end{tabular}

This framework of presuppositions is composed of three layers: firstly, in considering presuppositions related to the generic context, we have focused on basic human needs, which are universal across cultures. Secondly, in exploring presuppositions related to the situational context, we have considered the CP and PP. Presuppositions related to the $\mathrm{CP}$ and PP are specific manifestations of these basic needs. Some of these presuppositions are of a universal nature, and some may show different emphasis on certain aspects across different cultural backgrounds. Thirdly, when studying presuppositions related to the discourse context, we have investigated the textualisation principles. This third category is the textual means to fulfil what is specified in the second category of communicative rules and the first category of needs. Having outlined the three aspects of context for identifying presuppositions, we will discuss the functions of presupposition in translation and provide a case study in the next section.

\section{Presupposition in translation}

\subsection{Functions of presupposition in translation}

Concerning presuppositions in translation, the following observations have been made: firstly, the translator may not necessarily share the knowledge that the author presupposes their readers to have (Fawcett 1997:125). This then necessitates that translators undertake special research to acquire such knowledge. However, in most cases, translators merely carry out translation tasks based on their own presuppositions about the target readers and the target context. 
Secondly, translators must estimate to what extent the target readers are likely to share their presuppositions, which is "a difficult judgment to make and involves a delicate balancing act" (Fawcett 1997:125). The translator has two choices: either to patronise the target readers by treating them as if they know nothing and lack the means to find out, or to leave them "in the dark" by not supplying the necessary information to make sense of the text (Fawcett 1997:125). In other words, in order to translate a text properly, the translator needs to know what presuppositional information may be lacking in the target culture as well as what presuppositions exist in that culture which may influence the reception of the translation (Fawcett 1997:126). Therefore, presuppositions play an essential role in translators' decisionmaking processes regarding what information to provide and how to provide it. In fact, the presupposition discussed here covers much more than our definition, as the former has involved anything that could possibly be related to translation or communication, such as the knowledge the target readers have, and the information that is shared between translators and target readers; however, in this study, the discussion is restricted to the three levels of human needs, communication principles, and textualisation principles, as detailed in section 4 .

\subsection{Analysis of an advertisement translation}

In this section, we will analyse an excerpt from a bilingual advertisement for a restaurant according to the framework of presuppositions established in section 4, focusing on the use of second-person reference. What follows is the text which appears on the advertisement for the restaurant. (Note that a back-translation of the Chinese text into English appears immediately after the Chinese text.)

Chef Rene's philosophy is very simple, quality produce cooked precisely and presented with the minimum of fuss, utilizing the freshest and finest of products. La Terrasse is organizing an exquisite menu on the occasion of Le French May anniversary!

\section{主厨 Rene 相信食物质量才是餐厅的灵魂，无论对烹调手法还是材料 选择均一丝不苟，今年更为了庆祝法国五月欢度十五周年，特别为 您设计了一系列精选菜式, 富有品味的您又怎可错过这次一尝法式 风味的机会呢?}

['Chef Rene believes that the food quality is the soul of the restaurant. He is meticulous in cooking methods and choosing materials. Particularly, he has prepared a selected menu for you in order to celebrate the $15^{\text {th }}$ anniversary of French May. How can you, who are tasteful, miss this opportunity to try the French style?']

In both of the versions, direct address is applied. Addressing the readers directly involves them in the construction of textual meaning, which facilitates their understanding and enhances the textual effect. In this sense, it can be traced back to the presuppositions concerning the processibility, clarity, and expressibility of textualisation as stated in section 4.2.3. The use of direct address is intended to increase readers' participation in the communication and sympathy between the text producer and text recipients, which shows cooperation and politeness. Therefore, it is also related to the presupposition about readers' social/love needs and esteem 
needs. As to how the original readers and the target readers are addressed, this can be analysed in connection with the translator's presuppositions about the target readers' values, interests or expectations. A comparison of the two versions shows that second-person reference is handled flexibly in the translation. In the English version, no second-person pronoun is used; the text merely describes the chef's working philosophy without addressing anyone specific. Still, the last sentence can be interpreted as that the restaurant is preparing an exquisite menu for the customers: "La Terrasse is organizing an exquisite menu for you on the occasion of Le French May anniversary!" In this sense, it is also a case of second-person address. In the Chinese version, direct address is applied via the second-person pronoun “您” (nin, 'you'), a respectful form of address in Chinese, in the last sentence, “富有品味的您又怎可錯過這次一嘗法式風味 的機會呢?” ('How can you, who are tasteful, miss this opportunity to try the French style?').

Such flexibility in handling second-person reference in advertisement translation is closely related to translators' understanding or presupposition concerning how to address the target readers' social/love and esteem needs properly, show cooperation and politeness, win their favour, deepen their impression, and promote the product or service. It is possible that the quality of translation and the application of second-person reference are related to the individual translator's competence and preference of style. However, we believe that the translator has taken into account the target readers' needs and expectations, consciously or subconsciously, when making the decisions to adapt the ways of second-person reference; this is because he/she has clear aims in translating the advertisement, that is, to involve the target readers' participation, deepen their impression, win their favour, and promote the product. In this sense, the adaptations made about second-person reference in advertisement translation are considered to be in accordance with the target readers' needs and expectations.

As explained in section 4.2.2, an important politeness maxim for the Chinese readers states that one should show difference between the old and the young, or the superior and the subordinate, when addressing them. In other words, respect is presupposed to be shown to others, particularly to those who are superior in terms of age or social ranking. This is why the respectful form is applied in the Chinese text to address the potential customers. While the English system also mentions that one is supposed to show more agreement and sympathy with others, the ways to address others are not as specified as in the Chinese politeness maxims. How to properly address the readers is related to the satisfaction of their social/love needs and esteem needs. The difference in terms of addressing the readers in the two versions shows that the ways to satisfy the readers' needs differ across cultures, at least according to the translator's perceptions. In short, translators make decisions as to how to address the target readers properly according to their presuppositions about the target readers' needs and expectations, and analysing the textual differences can shed light on the translator's presuppositions which further help to reveal the nuanced cultural and linguistic differences.

\section{Conclusion}

In this research, we have elaborated on the concept of 'presupposition' with reference to translation studies, and discussed presuppositions which are closely related to context. Exploring presuppositions from the contextual perspective shows insight into translators' decision-making processes, and provides reference when analysing specific translations. Although the workings of presuppositions are often subconscious, translators can make conscious use of such presuppositions to produce more effective translations which are in line 
with the target readers' needs, values, interests, and expectations. In future research, the presuppositions analysed in this paper which are involved in translation can be further specified and tested.

\section{References}

Abbott, B. 2006. Where have some of the presuppositions gone? In B.J. Birner and G. Ward (eds.) Drawing the boundaries of meaning: Neo-Gricean studies in pragmatics and semantics in honor of Laurence R. Horn. Philadelphia: John Benjamins. pp. 1-20.

Brown, G. and G. Yule. 1983. Discourse analysis. Cambridge: Cambridge University Press.

Cui, Y. 2013. Presupposition revisited: The role of context. The Linguistics Journal 7(1): 189208.

Fawcett, P. 1997. Translation and language: Linguistic theories explained. Manchester: St. Jerome.

Fawcett, P. 1998. Presupposition and translation. In L. Hickey (ed.) The pragmatics of translation. Clevedon: Multilingual Matters Ltd. pp. 114-123.

Ferrari, L. and E. Sweetser. 2012. Subjectivity and upwards projection in mental space structure. In B. Dancygier and E. Sweetser (eds.) Viewpoint in language: A multimodal perspective. Cambridge: Cambridge University Press. pp. 47-64.

Fetzer, A. 2004. Recontextualizing context: Grammaticality meets appropriateness. Amsterdam and Philadelphia: John Benjamins.

Georgakopoulou, A. 1997. Discourse analysis: An introduction. Edinburgh: Edinburgh University Press.

Givón, T. 1989. Mind, code, and context: Essays in pragmatics. Hillsdale: Lawrence Erlbaum Associates.

Grice, H.P. 1975. Logic and conversation. In P. Cole and J.L. Morgan (eds.) Syntax and semantics, Vol. 3: Speech acts. New York: Academic Press. pp. 41-58.

Hickey, L. 1998. The pragmatics of translation. Shanghai: Shanghai Foreign Language Education Press.

Leech, G.N. 1983. Principles of pragmatics. London: Longman.

Levinson, S.C. 1983. Pragmatics. London/New York: Cambridge University Press.

Maslow, A.H. 1987. Motivation and personality. New York: Harper and Row. 
Mey, J. 2001. Pragmatics: An introduction. Beijing: Foreign Language Teaching and Research Press.

Muchinsky, P.M. 2003. Psychology applied to work: An introduction to industrial and organizational psychology. Belmont: Wadsworth.

Nord, C. 2001. Translation as a purposeful activity: Functionalist approaches explained. Shanghai: Shanghai Foreign Language Education Press.

Segerdahl, P. 1996. Language use: A philosophical investigation into the basic notions of pragmatics. London: Macmillan Press Ltd.

Stalnaker, R.C. 1998. Pragmatics. In A. Kasher (ed.) Pragmatics: Critical concepts. London: Routledge. pp. 55-70.

Stephens, D.C. 2000. The Maslow business reader. New York: J. Wiley.

Tannen, D. 2007. Talking voices: Repetition, dialogue, and imagery in conversational discourse. Cambridge: Cambridge University Press.

Widdowson, H.G. 1998. The conditions of contextual meaning. In M. Kirsten and J. Williams (eds.) Context in language learning and language understanding. Cambridge: Cambridge University Press. pp. 6-23.

Widdowson, H.G. 2004. Text, context, and pretext: Critical issues in discourse analysis. Malden, MA: Blackwell Publications.

Yang, B. 1999. Comments on difference between Chinese and Western politeness principle. Liuzhou Normal University Journal 1999(2): 33-35. 